\title{
Prediction of Windthrow Damage in Mixed Conifer-Broadleaf Stands via a Machine Learning Model
}

\author{
Vasiliki Dimou $^{1^{*}}$, Konstantinos Demertzis ${ }^{1,2^{*}}$, Apostolos Kantartzis ${ }^{1}$ \\ 1 Democritus University of Thrace, Department of Forestry \& Management of the Environment \& Natural Re- \\ sources, 193 Pandazidou, PC 68200 Orestiada, Greece; vdimou@fmenr.duth.gr; kdemertz@fmenr.duth.gr; ap- \\ kantar@fmenr.duth.gr \\ 1 School of Science \& Technology, Informatics Studies, Hellenic Open University, Greece; demertzis.konstanti- \\ nos@ac.eap.gr \\ * Correspondence: kdemertz@fmenr.duth.gr; demertzis.konstantinos@ac.eap.gr
}

\begin{abstract}
Management approaches inspired by the variability of natural disturbances are expected to produce forests in the future that will be significantly more resilient and better adapted to local environmental conditions. Due to climate change, windstorms are becoming increasingly common resulting in the destruction not only of extensive forest areas but, quite often, of small-sized and scattered forest lands that can ultimately become home to insects and disease dissemination sites. In the present study, an attempt is made to identify and record areas in the northeastern forests of Greece covered by mixed stands of conifers and broadleaves that experienced massive windthrow following local storms. Based on tree-level data, local topographic features, forest characteristics and the mechanical properties of green wood, a reliable model, to be used for the prediction of similar disturbances in the future, has been created after a thorough comparative study of the most well-known intelligent machine learning algorithms.
\end{abstract}

Keywords: wind damage; wind disturbance; Pinus sylvestris; Picea abies; machine learning; random forest

\section{Introduction}

Over the last years, windthrow has become an increasingly significant factor of natural disturbance. In recent decades, Europe has been hit by a series of severe storms. One such example is Cyclone Niklas, which, in March 2015, caused extensive damage to the forests of southern Germany. Severe storms are, unfortunately, predicted to become even more frequent in Europe as a result of climate change (Schelhaas et al. 2003; Seidl et al. 2014).

Research on the impact of windstorms on temperate forests has generally focused on the catastrophic disturbances related to the most severe winds (Dunn et al. 1983; Foster 1988; Peterson and Pickett 1991; Cooper-Ellis et al. 1999; Canham et al. 2001). The range of disruptions they bring to the forest vegetation is an important parameter affecting in the long run the composition and structure of ecological systems in general (Pickett and White 1985; Canham et al. 2001).

Uprooting (windthrow) and breakage of the tree trunk (windsnap) may cause local disturbance to the soil, as well as the formation of canopy gaps; the latter triggers the competition in that area by shade-intolerant and early successional species (JankowskaBlaszcuk and Grubb 2006). According to Böhm (1981), the composition and ratio of autochthonous to non-autochthonous species are altered, a fact that would entail a shift from deciduous trees to unstable conifers such as spruce (Schelhaas et al. 2003).

The short-term consequences of these disturbances include the damage incurred by the resulting insect communities, mainly the European spruce beetle [Ips typographus (L.)], thriving in the affected trees. More generally in Europe, both abiotic factors (windthrow) and biotic (bark beetle infestations) are serious causes of disturbance (Seidl et al. 2014). 
In a period of fifty years (1950-2000) the average annual damage to wood from storms in Europe amounted to 18.7 million $\mathrm{m}^{3}$, with most windthrow damage taking place in Central Europe and the Alps. For the same period, short-term wood damage from insect attacks amounted to 2.9 million $\mathrm{m}^{3}$ per year (Schelhaas et al. 2003). Taking the above into consideration, it becomes clear that windthrow forest areas must be identified as soon as possible in order to reduce the impact of the resulting biotic disturbance, as damaged trees yield substantial material for insect reproduction (Schelhaas et al. 2003; Seidl et al. 2014). More generally, delineating windthrow areas is deemed crucial both for the calculation of the damaged wood volume and in order to effectively schedule and plan the processing and marketing of the damaged wood to prevent its further degradation (Koloman 2013).

Identifying damaged sites and determining the extent of a wind disaster by means of terrestrial methods is often problematic, especially in the case of multiple and smallersized mosaic-like disturbed areas. For this reason, measurements conducted with the use of global navigation satellite systems (GNSS) are the most common for this task (Tomaštík 2016). Data collection can also be performed using unmanned aircraft systems (UAS), which can provide more accurate and detailed data compared to the existing remote sensing techniques (Tang 2015). UAS are characterized by high precision, flexibility, and ability to be used in various atmospheric conditions (Whitehead 2014). They have also been employed in a number of studies focusing on forest disturbance incidents, such as fires (Yuan 2015) and insect infestations (Näsi 2015). However, UAS have not been used to determine windstorm disturbed areas (Mokroš 2017). According to Vaudour et al. (2017), images obtained from the Pléiades satellite could be an alternative to UAS imagery but are more expensive for small-sized areas.

The present study is part of a broader, long-term research effort whose objective is to spatially assess the climate change experienced by Greece due to its geophysical location and diverse climate. Its aim is twofold: on one hand, the investigation and understanding of the role local topographic agents play in windthrow events, in combination with the characteristics and mechanical properties of green wood species that experience windthrow damage; on the other, the creation of a machine learning model which, once trained over the real data collected, will be capable of carrying out accurate predictions of future windthrow disasters under similar environmental and topographic conditions and with similar mechanical tree characteristics.

\section{Materials and Methods}

In April 2020, for three consecutive days (5 to 7 April), moderate to strong winds developed in locations northeast of the Rodopi Mountains, Northern Greece. On April 5, maximum wind gusts reached $187.5 \mathrm{~km} / \mathrm{h}$, and in the next two days, maximum gusts of $140.79 \mathrm{~km} / \mathrm{h}$ and $155.23 \mathrm{~km} / \mathrm{h}$, respectively, were recorded (www.wunderground.com). The main area that was hit is located to the NE of the City of Xanthi. The strong winds caused a heterogeneous damage pattern including uprooting and trunk breakage mainly in small-sized mosaic-type sites.

After the storm event, and in order to assess the extent of the damage and identify the storm-hit areas, an unmanned aircraft system (UAS) was used to scan an area of approximately $159 \mathrm{ha}$. Of the total of locations that were UAS-scanned, four sites were found to have been severely battered. These sites belonged to four mixed stands consisting of conifers and broadleaves located NE of the City of Xanthi. More specifically, in stand 27a (PsMxQu) (Table 1), where Pinus sylvestris trees occurred in mixtures with Quercus sp. (with neither of the two species being dominant), it was found that a specific plot, hereinafter referred to as 'plot aPISY', was seriously affected. In stand 26c (PsDomxQu), also made up of a mixed Pinus sylvestris and Quercus sp. community, the former being the dominant species, the corresponding damaged section was assigned the name 'plot bPISY'. In the third stand, stand 7a (FsDomxPs), consisting of a mixed Fagus sylvatica and Pinus sylvestris assemblage, with Fagus sylvatica being the dominant species, the damaged location was named 'plot aPIAB'. Finally, in the fourth stand, stand 7b (PsDomxFs), also 
consisting of mixed Pinus sylvestris and Fagus sylvatica trees, with Pinus sylvestris being the dominant species, the damaged site was named 'plot bPIAB'. To put it in a nutshell, the four stands were all mixed communities of conifers and broadleaves, in two of which (26c and $7 b$ ) conifers were the prevailing species, one (7a) was dominated by broadleaves, whereas in the fourth (27a) there was no dominant species. Plots aPISY and bPISY were composed solely of Pinus sylvestris, whereas the other two plots, aPIAB and bPIAB, were occupied by mixtures of Pinus sylvestris and Fagus sylvatica and also a number of Picea abies individuals as a secondary species.

Table 1 Summary of the windthrow areas (stands and plots)

\begin{tabular}{|c|c|c|c|c|c|c|}
\hline Name & Designation & Dominant species & $\begin{array}{l}\text { Secondary } \\
\text { species }\end{array}$ & Name of plot & $\begin{array}{l}\text { Stand } \\
\text { area } \\
(\mathrm{Ha})\end{array}$ & $\begin{array}{c}\text { Wood } \\
\text { volume } \\
\mathrm{m}^{3}\end{array}$ \\
\hline $\begin{array}{l}\text { (27a) Conifer-Hardwood } \\
\text { mixed species }\end{array}$ & PsMxQu & & & aPISY & 36.36 & 4987 \\
\hline $\begin{array}{l}\text { (26c) Conifer-Hardwood } \\
\text { mixed species }\end{array}$ & PsDomxQu & Ps dominated & & bPISY & 38.23 & 5496 \\
\hline $\begin{array}{l}\text { (7a) Hardwood-Conifer } \\
\text { mixed species }\end{array}$ & FsDomxPs & Fs dominated & $\begin{array}{l}\text { Picea abies+ } \\
\text { Prunus+Betula } \\
+ \text { Populus }\end{array}$ & aPIAB & 41.42 & 16198 \\
\hline $\begin{array}{l}\text { (7b) Conifer-Hardwood } \\
\text { mixed species }\end{array}$ & PsDomxFs & Ps dominated & $\begin{array}{c}\text { Picea abies+ } \\
\text { Prunus+Betula } \\
\text { +Populus }\end{array}$ & bPIAB & 42.98 & 15275 \\
\hline sum & & & & & 158.99 & \\
\hline
\end{tabular}

Ps=Pinus sylvestris, Fs=Fagus sylvatica

After identifying the four windthrow plots, a series of field measurements were carried out. These included: a) the totality of the damaged trees in all four locations, which were subsequently classified according to forestry species and type of damage per plot. It must be clarified here that in the current study, we took into account only the uprooted trees and not the broken ones; $b$ ) the diameter at breast height of the uprooted trees; and c) with the help of Garmin Dakota 20 GPS, the area, elevation, as well as the aspect of each affected plot.

In order to draw conclusions pertaining to the properties of green wood and the strength and resilience of the species that were affected (Pinus sylvestris and Picea abies) as well as of those which were within the windthrow stands but did not experience any damage (Fagus sylvatica and Quercus sp.), the Stuttgart Table of Wood Strength (Wessolly and Erb 1998) was taken into account for the species concerned. This list (Table 2) refers to the mechanical properties of green wood (i.e., standing wood) and not of wood in use.

Table 2 Stuttgart table of wood strength (Wessolly and Erb 1998)

\begin{tabular}{|c|c|c|c|c|}
\hline Species & $\begin{array}{c}\text { Modulus of elasticity } \\
\left(\mathrm{N} / \mathrm{mm}^{2}\right)\end{array}$ & $\begin{array}{c}\text { Comparable strength in } \\
\text { longitude } \\
\left(\mathrm{N} / \mathrm{mm}^{2}\right)\end{array}$ & $\begin{array}{c}\text { Elastic limit } \\
(\%)\end{array}$ & $\begin{array}{c}\text { Proposed Aerodynamic } \\
\text { drag factor }\left(\mathrm{C}_{w}\right)\end{array}$ \\
\hline $\begin{array}{c}\text { Pinus } \\
\text { sylvestris }\end{array}$ & 5800 & 17.0 & 0.29 & 0.15 \\
\hline Picea abies & 9000 & 21.0 & 0.23 & 0.20 \\
\hline
\end{tabular}




\begin{tabular}{|c|c|c|c|c|}
\hline $\begin{array}{c}\text { Fagus } \\
\text { sylvatica }\end{array}$ & 8500 & 22.5 & 0.26 & $0.25-0.30$ \\
\hline $\begin{array}{c}\text { Quercus } \\
\text { robur }\end{array}$ & 6900 & 28.0 & 0.41 & 0.25 \\
\hline
\end{tabular}

\subsection{Intelligent Data Analysis}

In order to create a forecasting model for the prediction of storm disasters based on tree-level data, a comprehensive comparative study of the most well-known machine learning algorithms was carried out. Machine learning is one of the most important and most widely used fields of artificial intelligence that includes computational methods of studying and building algorithms that can learn from appropriate data sets and, based on this experience, carry out accurate future forecasts.

In recent years, machine learning has been used in various environmental issues, such as the exploration of the impact of climate change on biodiversity (Demertzis and Iliadis 2018), the modeling of forest fires (Anezakis et al. 2018), the analysis of exhaust emissions generated by chainsaws (Dimou et al. 2018), and the prediction of interior spruce wood density utilizing progeny test information (Demertzis et al. 2017).

The concept of experience mentioned above refers to the hidden knowledge included in the field data we collected, which are related to local topographic factors, forestry characteristics as well as the mechanical properties of species in association with the type of damage they suffered. To be more specific, we used as independent variables the characteristics related to the topographic area, the size of the damaged sites, the forestry species, diameter at breast height, slope and geographic orientation. The only dependent variable that we used was whether the tree was uprooted or not. Consequently, we came up with a binary classification problem (Bahel et al. 2020).

Binary classification concerns the grouping of each sample into one of two predetermined classes. The term 'training' of a machine learning model by means of the classification method refers to the process that calculates the equation $\hat{f}: R^{N} \rightarrow T$, where $\mathrm{T}$ is a set of labels that indicate the class (whether the tree was uprooted or not). In this problem, we considered as a key evaluation metric the error corresponding to an incorrect prediction, which depends on the concept of relative distance between the different classes (Canbek et al. 2017).

In general, evaluation metrics are used to measure the performance of a machine learning method. Without these evaluation metrics, there can be no comparison between algorithms, nor is there the potential to select the appropriate tune hyperparameters that allow the model to maximize model performance. Evaluation is carried out only in the unknown data (test set) as an algorithm may be consistent with the training set but fail to perform well in the test set (Raschka 2014).

\section{Results and Discussion}

\subsection{Results}

After scanning with the help of an UAS an area of approximately 159 ha (Table 1), four damaged plots were identified (aPISY, bPISY, aPIAB, bPIAB), each of which was located in a different stand. In the first two plots (aPISY and bPISY), belonging to two mixed stands of conifers and broadleaves, namely Pinus sylvestris and Quercus sp., damage had only occurred in Pinus sylvestris. In the other two plots (aPIAB and bPIAB), also belonging to another two mixed stands of Fagus sylvatica and Pinus sylvestris, damage had only occurred in the secondary species, i.e., Picea abies.

Table 3 illustrates the topographic features as well as the size of each plot, the largest of them being aPIAB with 5.75 ha. These plots are located at altitudes ranging from 1000 to $1300 \mathrm{~m}$. Table 4 shows the ranking of the severity of damage in these plots following the 
Bradford / Unwin damage scale (Unwin et al. 1988). According to this scale, damage equal to 1.5 is considered as serious disturbance. Plot aPISY, with a large number of trees being snapped or uprooted and the rest having undergone moderate disturbance, belongs to this class (Table 4). Damage equal to 1.0 corresponds to severe and extensive disturbance; plot bPISY falls into this class as all the trees it consisted of exhibited extensive disturbance.

Damage equal to 3 corresponds to moderate or minor disturbances; plot aPIAB belongs here, as fewer than $10 \%$ of the trees were damaged (Unwin et al. 1988; Metcalfe 2008). In this plot, 160 Picea abies trees were affected, $88.75 \%$ of which were uprooted and the remaining snapped. Last, plot bPIAB belongs to scale 2.5 , which is considered to represent instances of moderate disturbance, where fewer than $33 \%$ of the trees were found to be broken or uprooted. Table 4 also shows the diameters at breast height of the uprooted trees as well as the wood volumes of the uprooted trees per plot.

Table 3 Topographic features and size of plots

\begin{tabular}{|c|c|c|c|c|c|c|c|}
\hline Plots & Latitude & Longitude & Geology & Aspect & Altitude & Slope $(\%)$ & Area $(\mathrm{Ha})$ \\
\hline aPISY* & $41^{\circ} 15^{\prime} 46^{\prime \prime} \mathrm{N}$ & $024^{\circ} 45^{\prime} 48^{\prime \prime} \mathrm{E}$ & granite & SW & 1000 & 10 & 1.20 \\
\hline bPISY & $41^{\circ} 15^{\prime} 32^{\prime \prime} \mathrm{N}$ & $024^{\circ} 46^{\prime} 06^{\prime \prime} \mathrm{E}$ & granite & $S$ & 1000 & 40 & 4.10 \\
\hline $\mathrm{aPIAB}^{* *}$ & $41^{\circ} 20^{\prime} 37^{\prime \prime} \mathrm{N}$ & $024^{\circ} 42^{\prime} 21^{\prime \prime} \mathrm{E}$ & rhyolite & NW & 1300 & 20 & 5.75 \\
\hline bPIAB & $41^{\circ} 20^{\prime} 40^{\prime \prime} \mathrm{N}$ & $024^{\circ} 42^{\prime} 22^{\prime \prime} \mathrm{E}$ & rhyolite & NW & 1300 & 20 & 0.26 \\
\hline sum & & & & & & & 11.31 \\
\hline
\end{tabular}

*Pinus sylvestris, ${ }^{* *}$ Picea abies

Table 4 Damage severity according to Bradford/Unwin damage scale, number of damaged trees per plot, type of damage, damage in $\mathrm{m}^{3}$

\begin{tabular}{|c|c|c|c|c|c|c|}
\hline Plot & $\begin{array}{c}\text { Bradford/Unwin } \\
\text { damage scale }\end{array}$ & $\begin{array}{l}\text { Level of } \\
\text { damage }\end{array}$ & $\begin{array}{l}\text { Number } \\
\text { of stems } \\
\text { assessed }\end{array}$ & $\begin{array}{c}\% \\
\text { uprooting }\end{array}$ & DBH (SD) & $\begin{array}{c}\text { Damage } \\
\mathrm{m}^{3} / \text { species }\end{array}$ \\
\hline aPISY(27a) & $1.5(95 \%)^{*}$ & Severe & 26 & 65.38 & $23.33(4.43)$ & 4.69 \\
\hline bPISY(26c) & $1(100 \%)$ & Severe & 237 & 39.66 & $21.46(2.28)$ & 33.08 \\
\hline $\operatorname{aPIAB}(7 a)$ & $3(9 \%)$ & Moderate & 160 & 88.75 & $26.07(8.00)$ & 77.88 \\
\hline $\mathrm{bPIAB}(7 \mathrm{~b})$ & $2.5(20 \%)$ & Moderate & 34 & 52.94 & $\begin{array}{l}25.27 \\
(8.28) \\
\end{array}$ & 9.19 \\
\hline sum & & & 457 & & & 124.84 \\
\hline
\end{tabular}

(\%) ${ }^{*}$ percentage of damaged trees, ${ }^{* *}$ uprooted trees $\left(\mathrm{m}^{3}\right)$

Table 5 Number of damaged trees per species

\begin{tabular}{|l|l|l|}
\hline & Number of all stems assessed $(\%)$ & Number per forestry species assessed $(\%)$ \\
\hline PISY uprooting & $111 / 457(24.29)$ & $111 / 263(42.20)$ \\
\hline PIAB uprooting & $160 / 457(35.01)$ & $160 / 194(82.47)$ \\
\hline
\end{tabular}

Table 5 depicts the total number as well as the percentage of the uprooted trees per species (111 Pinus sylvestris, 160 Picea abies) compared to the total number of damaged trees (457), which includes both the uprooted and snapped trees; the latter, however, were not taken into consideration in the present study. The table also shows ( $3^{\text {rd }}$ column) the number and percentage of the uprooted trees per species (263 Pinus sylvestris, 194 Picea abies) compared to the total number of uprooted trees. 


\subsubsection{Machine Learning Performance Comparison Results}

In the present study, the following machine learning methods were evaluated and compared: Random Forest Classifier, k-Neighbors Classifier, Decision Tree Classifier, Light Gradient Boosting Machine, Gradient Boosting Classifier, Ada Boost Classifier, Ridge Classifier, Linear Discriminant Analysis, Logistic Regression, Naive Bayes, SVM Linear Kernel and Quadratic Discriminant Analysis. In order to get the best predictive model, the different machine learning algorithms were evaluated based on six performance metrics (confusion matrix, accuracy, precision, recall, F-score, and ROC). Table 6 illustrates the results of the comparative study.

Table 6 Machine Learning Performance Comparison Results

\begin{tabular}{|c|c|c|c|c|c|c|c|}
\hline ID & Algorithm & Accuracy & ROC & Recall & Precision & F-Score & TT (Sec) \\
\hline 1. & Random Forest Classifier & 0.8851 & 0.9476 & 0.8677 & 0.8975 & 0.8820 & 0.610 \\
\hline 2. & k-Neighbors Classifier & 0.8838 & 0.9433 & 0.8719 & 0.8917 & 0.8811 & 0.126 \\
\hline 3. & Decision Tree Classifier & 0.8827 & 0.9030 & 0.8573 & 0.9019 & 0.8785 & 0.020 \\
\hline 4. & Light Gradient Boosting Machine & 0.8745 & 0.9450 & 0.8407 & 0.8997 & 0.8689 & 0.121 \\
\hline 5. & Gradient Boosting Classifier & 0.8468 & 0.9221 & 0.7874 & 0.8909 & 0.8356 & 0.192 \\
\hline 6. & Ada Boost Classifier & 0.7662 & 0.8480 & 0.6655 & 0.8288 & 0.7376 & 0.160 \\
\hline 7. & Ridge Classifier & 0.7559 & 0.0000 & 0.6634 & 0.8091 & 0.7286 & 0.016 \\
\hline 8. & Linear Discriminant Analysis & 0.7559 & 0.7625 & 0.6634 & 0.8091 & 0.7286 & 0.020 \\
\hline 9. & Logistic Regression & 0.7542 & 0.7687 & 0.6565 & 0.8110 & 0.7253 & 0.359 \\
\hline 10. & Naive Bayes & 0.7391 & 0.7773 & 0.6856 & 0.7635 & 0.7220 & 0.018 \\
\hline 11. & SVM - Linear Kernel & 0.6370 & 0.0000 & 0.7686 & 0.6947 & 0.6735 & 0.030 \\
\hline 12. & Quadratic Discriminant Analysis & 0.5146 & 0.4607 & 0.1215 & 0.8495 & 0.1078 & 0.018 \\
\hline
\end{tabular}

The algorithm with the best predictive performance as reflected in Table 6 above was found to be Random Forest (RF) (Prinzie and Poel 2007). RF uses decision trees as predictive models, to which it assigns comments and conclusions regarding the target value of the dependent variable. Each decision tree is calculated by induction, based on the recorded data, using the divide-and-conquer technique. More specifically, for the data set considered in the present paper, each data includes seven independent variables and there are a total of two classes $\left(C_{1}, C_{2}\right)$ as independent variables (uprooted vs. not uprooted).

The objective is the partition of the set into subsets, each of which comprises data belonging to a single class. In particular, a suitable test is selected, which typically uses a single feature, with only one output in the set $\left\{\mathrm{O}_{1}, \mathrm{O}_{2}, \ldots, \mathrm{O}_{n}\right\}$. In this way, the set is partitioned in subsets $T_{1}, T_{2}, \ldots, T_{n}$, where subset $T_{i}$ includes all the data of the initial set for 
which the $O_{i}$ output has been derived. So, the decision tree includes a decision node where the test selected is performed and a branch for each $\mathrm{O}_{1}, \mathrm{O}_{2}, \ldots, \mathrm{O}_{n}$ output. It should be stressed that the RF algorithm uses a large number of decision trees in order to correctly achieve the final categorization of the problem at hand.

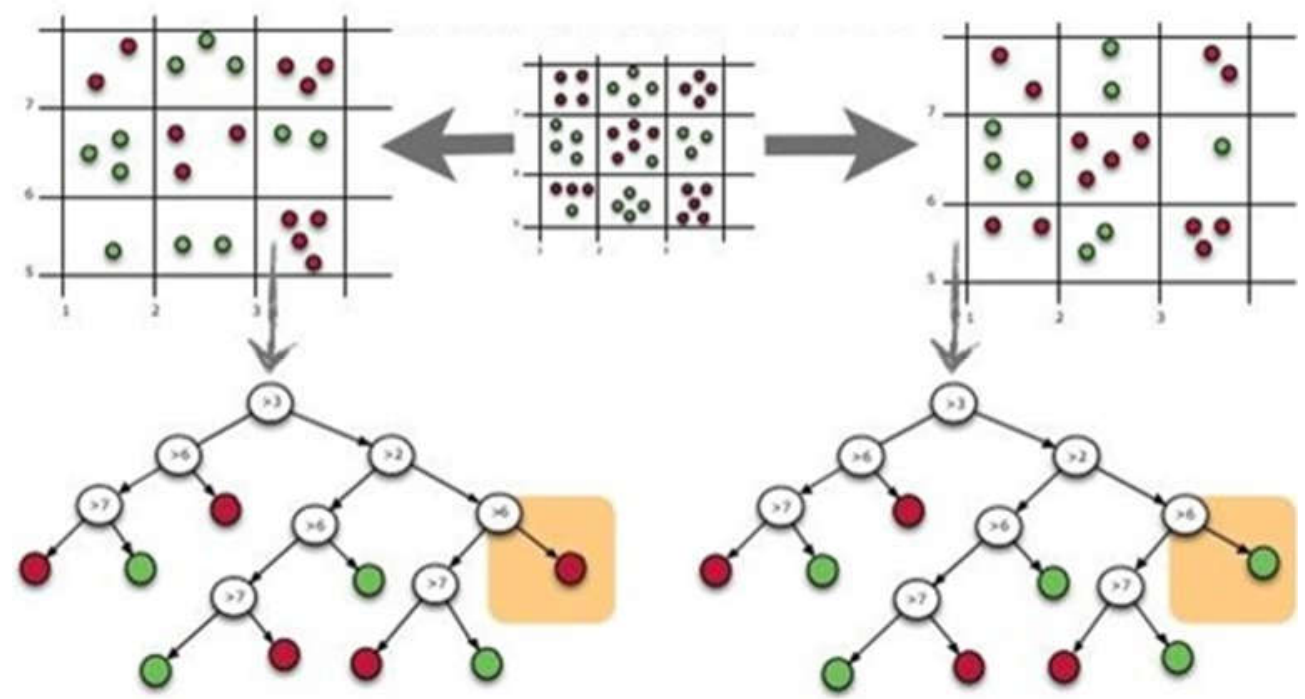

Fig. 1 Operation of Random Forest

As proof of the supremacy of the algorithm over the other candidates, the following schematic diagrams (Fig. 2-4 and Fig. 6-13 see appendix) are presented confirming the efficiency of the said algorithm. The most popular performance metrics that are capable of evaluating and comparing with clarity, thoroughness, and objectivity the classification algorithms used in this paper are presented below (Talingdan 2019):

1. Confusion Matrix

The evaluation of a classification model is based on the number of records in a test set that are predicted correctly or incorrectly by the model. This number is placed in a confusion matrix, a two-dimensional table, in which columns correspond to the predicted and rows to the actual values of each class.

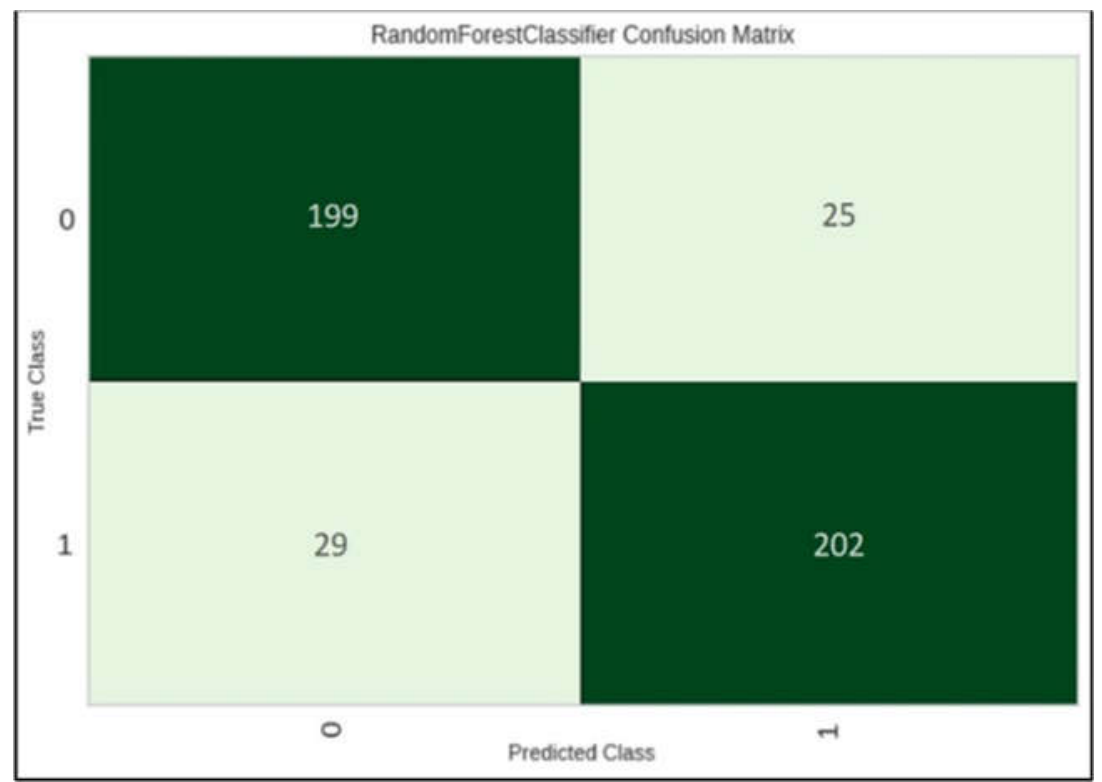

Fig. 2 Confusion Matrix

2. Accuracy 
Accuracy is calculated via the following equation:

and expresses the percentage of correct predictions.

$$
\text { accuracy }=\frac{T P+T N}{T P+T N+F P+F N}
$$

3. Precision

Precision is calculated as follows:

$$
\text { precision }=\frac{T P}{T P+F P}
$$

and expresses the percentage of the correct positive results predicted by the classifier. 4. Recall

Recall is calculated by means of the following equation:

$$
\text { recall }=\frac{T P}{T P+F N}
$$
sifier.

and expresses the classification percentage of all positive results classified by the clas-

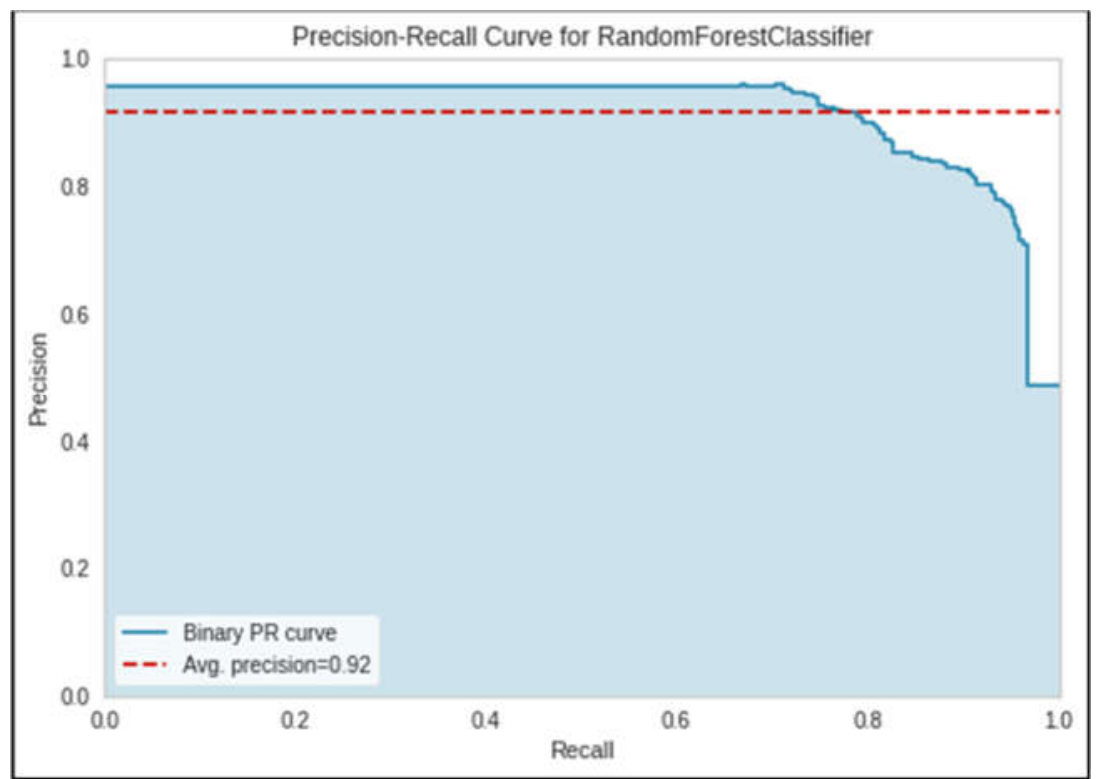

Fig. 3 Precision vs Recall

\section{F-Score}

In order to effectively deal with instances in which a classifier has high recall but low precision, the F-Score metric has been introduced, which is the harmonic mean between precision and recall and is calculated through the following equation:

$$
F_{\text {Score }}=\frac{2 \times \text { recall } \times \text { precision }}{\text { recall }+ \text { precision }}=\frac{2 T P}{2 T P+F P+F N}
$$

The greater the F-Score, the higher are recall and precision and the better is the performance of a given model. 


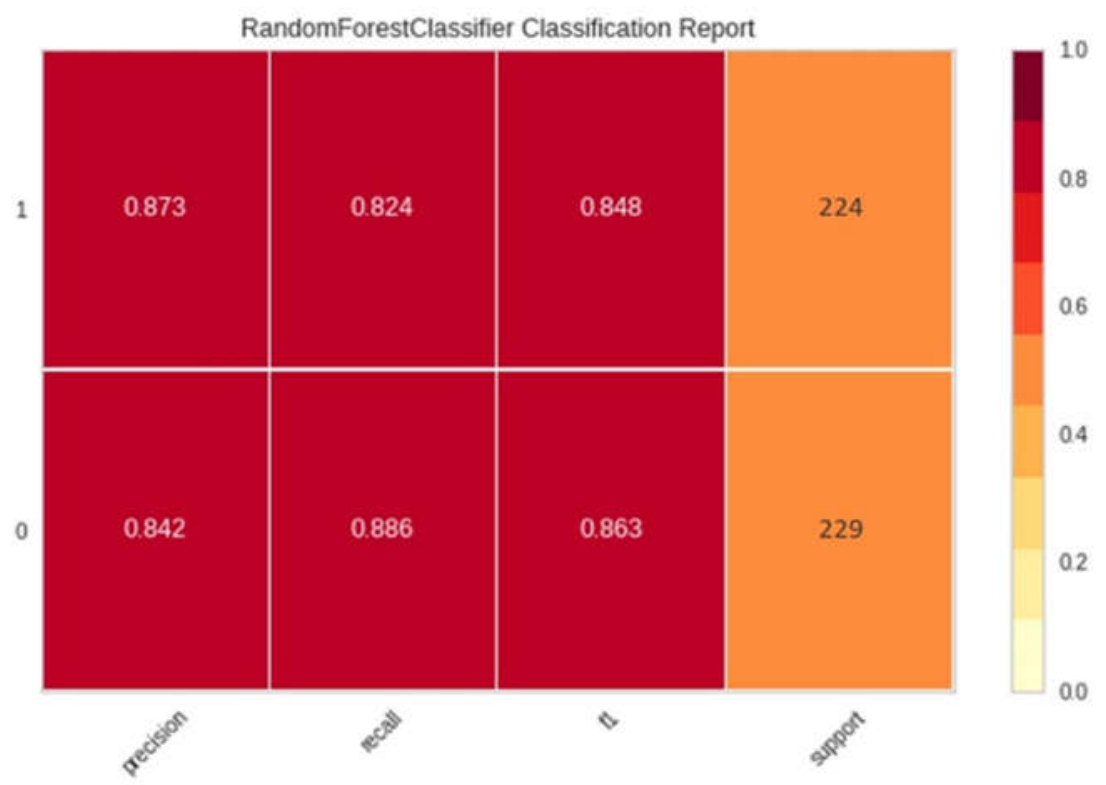

Fig. 4 Classification performance report

\section{6. $\quad$ Receiver Operating Characteristic (ROC)}

This metric can be applied in classifiers that have confidence as output. In this case, the classifier predicts a class if confidence in this class exceeds a given threshold. For the formation of the ROC curve, various threshold values are used and, each time, the rates [True Positive Rate (TPR) and False Positive Rate (FPR)] are recorded. These pairs of values are plotted in a graph, in which $y$ axis corresponds to TPR and $x$ axis corresponds to FPR. The performance of each classifier is represented as a point in the ROC curve (Alam et al. 2011).

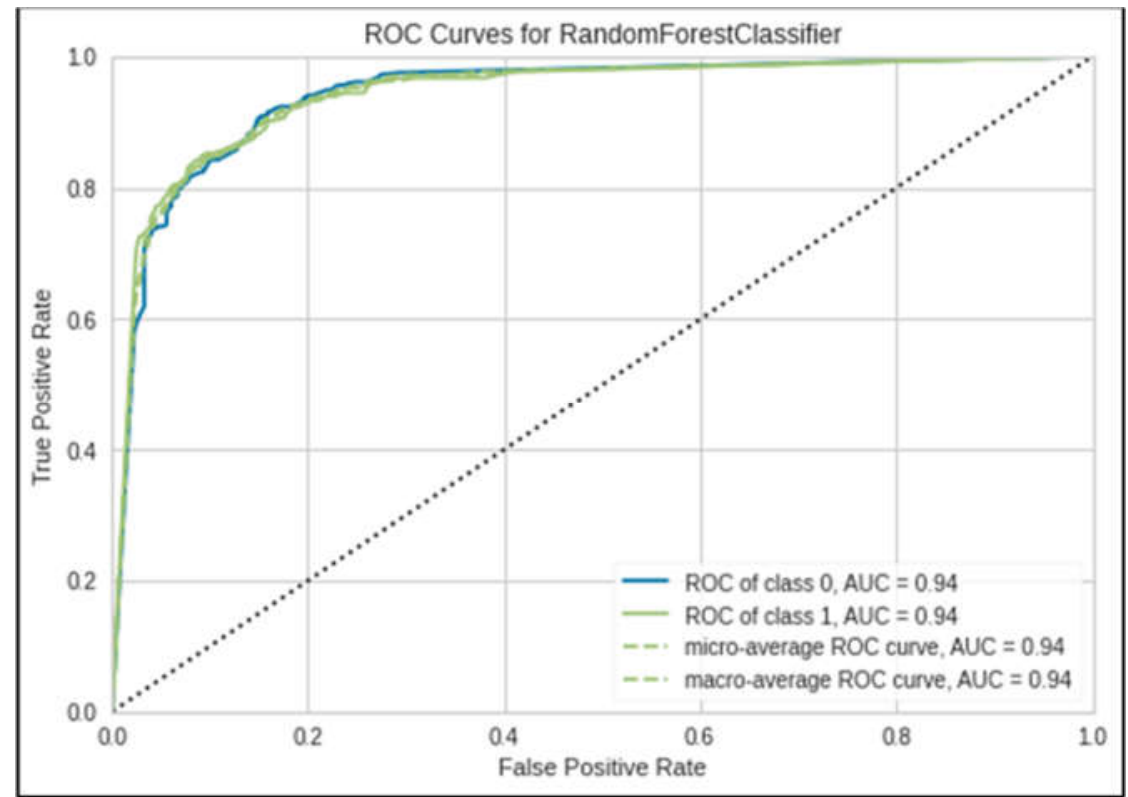

Fig. 5 ROC plots

\subsection{Discussion}

The Fujita (F) Scale is used to estimate tornado wind speeds based on the level of damage left behind by a tornado. The scale ranges from F0, assigned to tornadoes which generate "light damage", to F5, which is assigned to tornadoes causing "incredible 
damage". According to Canham et al. (2001), severe tornadoes rated F3-F5 on the Fujita scale with winds blowing at $>70 \mathrm{~m} / \mathrm{s}$ (Godfrey et al. 2017) may cause uniform and complete windthrow in a location with relatively distinct boundaries between the damaged area and an adjacent minimally disturbed site. The majority of tornadoes (almost 75\%) correspond to an F-scale rating of F0-F1 and are characterized by moderate winds $(<50 \mathrm{~m} / \mathrm{s})$; however, they are likely to bring about a wide range of catastrophic impacts on the affected trees. In the current research, carried out in an area NE of the City of Xanthi, on April 5, wind speeds were well below $50 \mathrm{~m} / \mathrm{s}(9.4 \mathrm{~m} / \mathrm{s})$ and blew constantly without pause for the next two days (6 and 7 April), on which speeds amounted to $11.8 \mathrm{~m} / \mathrm{s}$ and $10.7 \mathrm{~m} / \mathrm{s}$, respectively. These winds produced damage rated between F0-F1 on the Fujita scale (Godfrey et al. 2017).

In plots aPISY and bPISY, consisting solely of Pinus sylvestris, 95\% - 100\% of the trees were blown down. However, the greatest extent of uprooting measured in $\mathrm{m}^{3}$ of damaged wood (77.88 $\mathrm{m}^{3}$, Table 4$)$ occurred in plot $\mathrm{aPIAB}$, as it was the largest in size disturbed plot (5.75 ha, Table 3). As a rule, it was observed that in all four mixed stands of conifers and broadleaves (Table 1), only the conifers, i.e., Pinus sylvestris and Picea abies were affected, while the broadleaves (Fagus sylvatica and Quercus sp.) showed no signs of damage.

In the first two mixed stands (PsMxQu and PsDomxQu), both of which were made up of conifers and broadleaves (Pinus sylvestris and Quercus sp.), and more specifically, in plots aPISY and bPISY (corresponding to PsMxQu and PsDomxQu stands, respectively, Table 1), disturbance occurred only in Pinus sylvestris trees, as these plots were composed solely of Pinus sylvestris. In the other two mixed Pinus sylvestris and Fagus sylvatica plots, i.e., $\mathrm{aPIAB}$ and bPIAB (belonging to stands FsDomxPs and PsDomxFs, respectively), disturbance occurred only in a secondary species, namely Picea abies, a fact that can serve as proof that Fagus sylvatica is exceptionally resistant to overturning or breaking in the given weather conditions. This is true only if Fagus sylvatica is not affected by beech bark disease (Chaham et al. 2001), as in the present case.

More generally, where Pinus sylvestris was mixed either with Quercus sp. or with Fagus sylvatica (aPIAB, bPIAB), it had been substantially protected, while in those plots where it stood on its own (aPISY, bPISY) it had been extensively uprooted. On the other hand, Picea abies, even if it was mixed with Fagus sylvatica and Pinus sylvestris, had been blown down to a large extent.

The ability of a tree to withstand trunk breakage is determined by the applied load (wind speed), tree geometry (crown sail-area and stem taper), as well as the mechanical properties of green wood, i.e., compression strength and modulus of elasticity (Horáček 2003). Taking into consideration the fact that the mechanical properties of green (moist) wood differ from those of industrial wood (Brudi et al. 2002), we used the corresponding green wood values in accordance with the Stuttgart table of wood strength (Wessolly and Erb 1998) and, in particular, those for Pinus sylvestris, Picea abies, Fagus sylvatica and Quercus sp. (Table 2). Wessolly and Erb (1998) studied the behavior of standing trees by means of an elastometer and derived the values of the mechanical properties of green (moist) wood (Horáček 2003).

Stiffness, measured by the modulus of elasticity $\left(\mathrm{N} / \mathrm{mm}^{2}\right)$, is the only constant of materials that is responsible for the behavior of the trunk under load stress such as the power of the wind. The destruction of a trunk takes place when the wind-induced stress on the marginal fibers of the trunk exceeds the tree's resistance to compression and this capacity to withstand loads is referred to as compression strength.

The resistance of a tree's crown to the wind is also expressed by means of the aerodynamic drag factor $\left(c_{w}\right)$. The drag factor shows that during a storm, the leaves, branches, and smaller twigs are bent by powerful air gusts (Mayhead 1973). Fagus sylvatica's green wood is significantly more rigid $\left(E_{\bmod }=8500 \mathrm{~N} / \mathrm{mm}^{2}\right)$ and has stronger compressive properties (22.5N/mm²) than Pinus sylvestris and Picea abies; also, the green wood of Quercus sp. has the highest compression strength $\left(28 \mathrm{n} / \mathrm{mm}^{2}\right)$ compared to the other three species.

In addition, both broadleaved species have very high aerodynamic drag factor values $\left(c_{w}=0.25-0.30\right.$ and $c_{w}=0.25$ for Fagus sylvatica and Quercus $s p$. , respectively), with $c_{w}=0.30$ 
being the maximum limit. Pinus sylvestris does not have very high stiffness values $\left(E_{\bmod }=5800 \mathrm{~N} / \mathrm{mm}^{2}\right)$ or particularly strong compressive properties $\left(17 \mathrm{~N} / \mathrm{mm}^{2}\right)$ and at the same time exhibits a relatively low aerodynamic drag factor $\left(c_{w}=0.15\right)$, a fact that justifies the high rates of Pinus sylvestris uprooting (42.20\%).

Picea abies, on the other hand, is more resistant to external loads (Emod=9000 N/mm²) compared to Pinus sylvestris, so it can be considered that its green wood is more rigid and has stronger compressive properties $\left(21 \mathrm{~N} / \mathrm{mm}^{2}\right)$; its aerodynamic drag factor has a moderate value $\left(c_{w}=0.20\right)$, which is by all means higher than that of Pinus sylvestris $\left(c_{w}=0.15\right)$. The high rates of uprooting in this species $(82.47 \%)$ are probably due to the fact that Picea abies is shallow rooted.

\section{Conclusion}

In the disturbed area, located NE of the City of Xanthi, Pinus sylvestris and Picea abies individuals suffered damage from stormy winds blowing for three consecutive days with maximum gusts reaching $187.5 \mathrm{~km} / \mathrm{h}$ (on April $5^{\text {th }}$ ) and maximum wind speeds equal to $11.8 \mathrm{~m} / \mathrm{s}$. According to the Fujita scale, the above wind speeds are ranked F0-F1, a category comprising almost 75\% of tornadoes (Godfrey 2017). As the winds were not considered to be particularly strong, the disturbance caused was not significantly extensive. Four plots in the study area were affected with a total area equal to 11.31ha (Table 3). The damage due to uprooting amounted to $124.84 \mathrm{~m}^{3}$ of wood (Table 4), while the overall damage including windsnap, too, was $187.77 \mathrm{~m}^{3}$.

Identifying the plots where the damage occurred was a problematic task as these areas were small-sized and scattered, and consequently it was highly unlikely that they could be identified through satellite. In order to identify the disturbed plots, an unmanned aircraft system (UAS) was used in the present study, as these systems are, as a rule, flexible and easy to use. It is beyond doubt that it is of crucial importance to quickly detect all damaged trees from abiotic causes such as wind disturbance even if they are scattered and in small areas as they constitute habitats to bark beetles (Seidl et al. 2014).

While recording and analyzing the information we collected about the damaged trees, it became easily evident that Picea abies is highly unstable and therefore easily uprooted even in low wind speeds, and its individuals are unable to be protected even if it is a secondary species within mixed conifer-broadleaf clusters. According to the Stuttgart table of wood strength (Wessolly and Erb 1998), the green wood of Picea abies has relatively good mechanical resistance and presents sufficient stiffness (Emod=9000 N/mm²) but its easy uprooting is due to its shallow root system that provides rather poor anchorage (Puhe 2003).

It was also found that, unlike Picea abies, under the same wind conditions, Pinus sylvestris experienced disturbance not individually but only in relatively small plots (1.20 ha and 4.10 ha, respectively, was the total area of plots aPISY and bPISY, where almost all Pinus sylvestris trees [95\% and 100\%, respectively] had been damaged). From on-site research, the authors assumed that a large proportion of damage within the respective plots can be attributed to trees falling on their neighbors (Metcalfe 2008). It was also found that in those cases where Pinus sylvestris was mixed with Fagus sylvatica in a cluster, it had been protected, whereas if it stood alone, it was damaged. Taking into account the fact that wind speeds were not exceptionally high as compared to those in other disturbed areas, it can also be assumed that the topographic conditions of the plots (slope, aspect, etc.) played a role in affecting local wind conditions, such as speed and pressure (Metcalfe 2008; Einzmann 2017; Brudi et al. 2002).

Given the global climate change situation, the approaches to be adopted for the optimal management of forests should revolve around goals of forest resilience and effective adaptation to future demanding environmental conditions. The authors of the current study believe that the windthrow data provided herein will benefit policy decision makers regarding risk management and forest planning. To this end, the following recommendations might prove useful. 
It is deemed necessary to opt for mixed forests and avoid large monoculture patches where a certain species develops on its own, as in the case of Pinus sylvestris, since it has been shown that even in relatively low wind intensities there may be serious tree damage; it is also recommended that Picea abies be avoided as it is particularly susceptible to windthrow even in relatively low wind intensities and it is hardly protected even in a mixed conifer-broadleaf community.

The data collected was used to develop a realistic machine learning model which adopts an RF algorithm in order to predict windthrow in similar conditions. The methodology of the proposed information system utilizes and expands the most technologically advanced forestry methods, as it takes advantage of the hidden knowledge lying in environmental data in order to add to climate change analysis methods and optimal decisionmaking mechanisms associated with it.

Author Contributions: Conceptualization, V.D. and AK.; methodology, K.D.; software, K.D.; validation, V.D., K.D. and AK.; formal analysis, V.D., K.D. and AK.; data curation, V.D., K.D. and AK.; writing-original draft preparation, V.D., K.D. and AK.; writing-review and editing, V.D., K.D. and AK.; visualization, K.D.; supervision, V.D.; project administration, V.D. All authors have read and agreed to the published version of the manuscript.

Funding: This research received no external funding.

Data Availability Statement: Not applicable.

Acknowledgments: The authors wish to express their sincere gratitude for their cooperation to the staff of the Forest Service of Xanthi. This synergy contributed to a great extent to the implementation of the current research project. We hope that the research will contribute to the existing body of knowledge and raise awareness among forest managers. The authors also wish to thank Mrs. Malivitsi Zoe for editing the paper.

Conflicts of Interest: The authors declare no conflict of interest.

\section{References}

1. Alam S, Olabiyi O, Annamalai A (2011) Energy detector's performance evaluation in a relay based cognitive radio network: Area under the ROC curve (AUC) approach, 2011 IEEE GLOBECOM Workshops (GC Wkshps), pp. 338-342, doi: 10.1109/GLOCOMW.2011.6162466.

2. Anezakis VD, Demertzis K, Iliadis L, Spartalis S (2018) Hybrid intelligent modeling of wild fires risk. Evolving Systems 9 , 267-283 https://doi.org/10.1007/s12530-017-9196-6

3. Bahel V, Pillai S, Malhotra M (2020) A Comparative Study on Various Binary Classification Algorithms and their Improved Variant for Optimal Performance, 2020 IEEE Region 10 Symposium (TENSYMP), pp. 495-498, doi: 10.1109/TENSYMP50017.2020.9230877.

4. Böhm P (1981) Sturmschäden in Schwaben von 1950 bis 1980. Allg. Forstz., 36, 1380.

5. Brudi E, Wassenaer P (2002) Trees and statics: non-destructive failure analysis. International Society of Arboriculture, Champaign, pp 53-70.

6. Canbek GS, Sagiroglu S, Temizel TT, Baykal N (2017) Binary classification performance measures/metrics: A comprehensive visualized roadmap to gain new insights, International Conference on Computer Science and Engineering (UBMK), pp. 821-826, doi: 10.1109/UBMK.2017.8093539.

7. Canham CD, Papaik MJ, Latty EJ (2001) Interspecific variation in susceptibility to windthrow as a function of tree size and storm severity for northern hardwood tree species. Canadian Journal of Forest Research, 31, 1-10.

8. Cooper-Ellis S, Foster DR, Carlton G, Lezberg A (1999) Forest response to catastrophic wind: results from an experimental hurricane. Ecology, 80: 2683-2696.

9. Demertzis K, Iliadis L (2018) The Impact of Climate Change on Biodiversity: The Ecological Consequences of Invasive Species in Greece. In: Leal Filho W., Manolas E., Azul A., Azeiteiro U., McGhie H. (eds) Handbook of Climate Change Communication: Vol. 1. Climate Change Management. Springer, Cham. https://doi.org/10.1007/978-3-319-69838-0_2

10. Demertzis K, Iliadis L, Avramidis S. et al. (2017) Machine learning use in predicting interior spruce wood density utilizing progeny test information. Neural Comput \& Applic 28, 505-519 https://doi.org/10.1007/s00521-015-2075-9

11. Dimou V, Anezakis VD, Demertzis K. et al. (2018) Comparative analysis of exhaust emissions caused by chainsaws with soft computing and statistical approaches. Int. J. Environ. Sci. Technol. 15, 1597-1608. https://doi.org/10.1007/s13762-0171555-0

12. Dunn CP, Guntenspergen GR, Dorney JR (1983) Catastrophic wind disturbance in an old-growth hemlock-hardwoodforest, Wisconsin. Can. J. Bot. 61: 211-217. 
13. Einzmann K, Immitzer M, Böck S, Bauer O, Schmitt A, Atyberger C (2017) Windthrow Detection in European Forests with Very High-Resolution Optical Data.

14. Foster DR (1988) Disturbance history, community organization and vegetation dynamics of the old-growth Pisgah Forest, south-western New Hampshire, U.S.A. J. Ecol. 76: 105-134.

15. Glitzenstein JS, Harcombe PA (1988) Effects of the December 1983 tornado on forest vegetation of the Big Thicket, southeast Texas, USA. For. Ecol. Manage. 25: 269-290.

16. Godfrey CM, Peterson CJ (2017) Estimating Enhanced Fujita Scale Levels Based on Forest damage Severity. American Meteorological Society. 32, 243-252, DOI: 10.1175/WAF-D-16-0104.1.

17. Horáček P (2003) Introduction to Tree Statics \& Static Assessment Presentation. Department of Wood Science, Faculty of forestry and Wood Technology Mendel University of Agriculture and forestry Brno; Czech Republic. Skript.

18. Jankowska-Blaszczuk M, Grubb PJ (2006) Changing perspectives on the role of the soil seed bank in northern temperate deciduous forests and in tropical lowland rainforests: parallels and contrasts. Perspect. Plant Ecol.Evol.Syst.8,3-21.

19. Koloman P, Strelec L (2013) Time minimizing transportation of calamity fallen timber. AIP Conf. Proc., 1558, $1843-1846$.

20. Mayhead GJ (1973) Some drag coefficients for British forest trees derived from wind tunnel studies. Agricultural Meteorology 12:123-130.

21. Metcalfe DJ, Bradford GB, Ford AJ (2008) Cyclone damage to tropical rain forest: Species-and community-level impacts. Austral Ecology 33, 432-441.

22. Mokroš M, Výbošt'ok J, Merganic J, Hollaus M, Barton I, Koren M, Tomaštík J, Cernava J (2017) Early Stage Forest Windthrow Estimation Based on Unmanned Aircraft System Imagery. Forest J. doi:10.3390/f8090306.

23. Peterson CJ, Pickett S.T.A (1991) Treefall and resprouting following catastrophic windthrow in an old-growth hemlockhardwoods forest. For. Ecol. Manage. 42: 205-218.

24. Pickett S.T.A, White PS (1985) Patch dynamics: a synthesis. The Ecology of Natural Disturbance and Patch Dynamics (eds S.T.A. Pickett \& P.S. White), pp. 371-384. Academic Press, Orlando, FL.

25. Prinzie A, Poel D (2007) Random Multiclass Classification: Generalizing Random Forests to Random MNL and Random NB. Database and Expert Systems Applications. Lecture Notes in Computer Science. 4653, p. 349. doi:10.1007/978-3-54074469-6_35. ISBN 978-3-540-74467-2.

26. Puhe J (2003) Growth and development of the root system of Norway spruce (Picea abies) in forest stands - a review. Forest Ecology and Management, 175 (1-3), 253-273.

27. S. Raschka S (2014) An Overview of General Performance Metrics of Binary Classifier Systems, ArXiv14105330 Cs, Oct. 2014, Accessed: Nov. 09, 2021. [Online]. Available: http://arxiv.org/abs/1410.533

28. Schelhaas MJ, Nabuurs GJ, Schuck A (2003) Natural disturbances in the European forests in the 19th and 20th Centuries. Glob. Chang. Biol. 9, 1620-1633.

29. Seidl R, Rammer W (2016) Climate change amplifies the interactions between wind and bark beetle disturbances in forest landscapes. Landsc. Ecol., 1-14.

30. Seidl R, Schelhaas MJ, Rammer W, Verkerk PJ (2014) Increasing forest disturbances in Europe and their impact on carbon storage. Nat. Clim. Chang., 4, 806-810.

31. Talingdan JA (2019) Performance Comparison of Different Classification Algorithms for Household Poverty Classification, 2019 4th International Conference on Information Systems Engineering (ICISE), pp. 11-15, doi: 10.1109/ICISE.2019.00010.

32. Tang L, Shao G (2015) Drone remote sensing for forestry research and practices. J. For. Res., 26, 791-797.

33. Tomaštík J, Tomaštík J, Salon Š, Piroh R (2016) Horizontal accuracy and applicability of smart phone GNSS positioning in forests. Forestry, 90, 187-198.

34. Unwin GL, Applegate GB, Stocker GC. Nicholson DI (1988) Initial effects of tropical cyclone 'Winifred' on forests in north Queensland. Proc. Ecol. Soc. Aust.15, 283-96.

35. Vaudour E, Leclercq L, Gilliot JM, Chaignon B (2017) Retrospective 70 y-spatial analysis of repeated vine mortality patterns using ancient aerial time series, Pléiades images and multi-source spatial and field data. Int. J. Appl. Earth Obs. Geo inf. 2017, 58, 234-248.

36. Weatheronline.gr.httpsQ//www.weatheronlin.gr/cgi-app/sailing?133\&LANG=gr\&WIND= accessed on 5-6-2020.

37. Wessolly L, Erb M (1998) Handbuch der Baumstatik und Baumkontrolle. Patzer Verlag, Berlin, Germany.

38. Yuan C, Zhang Y, Liu Z (2015) A survey on technologies for automatic forest fire monitoring, detection, and fighting using unmanned aerial vehicles and remote sensing techniques. Can. J. For. Res., 45, 783-792. 


\section{Appendix A}

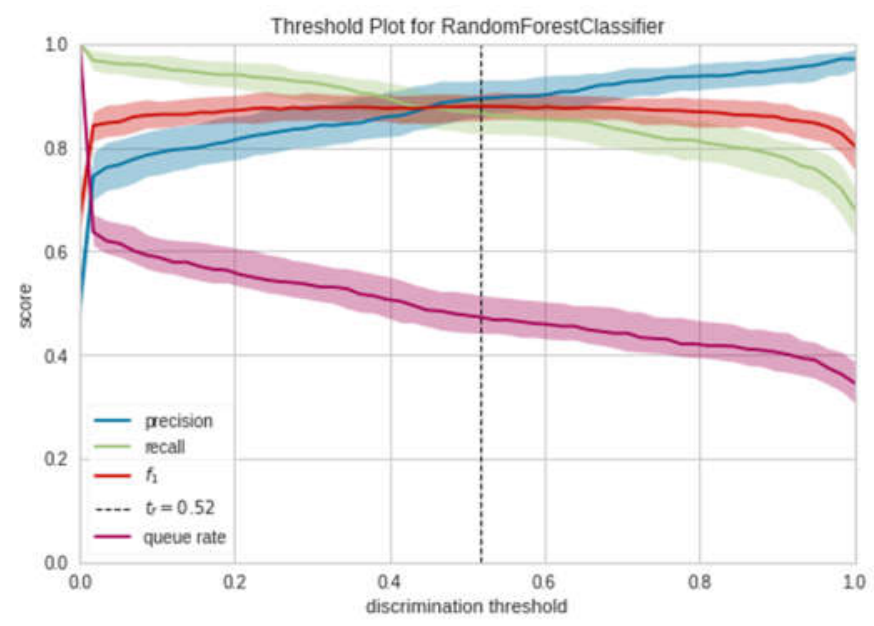

Fig. 6 Threshold plot

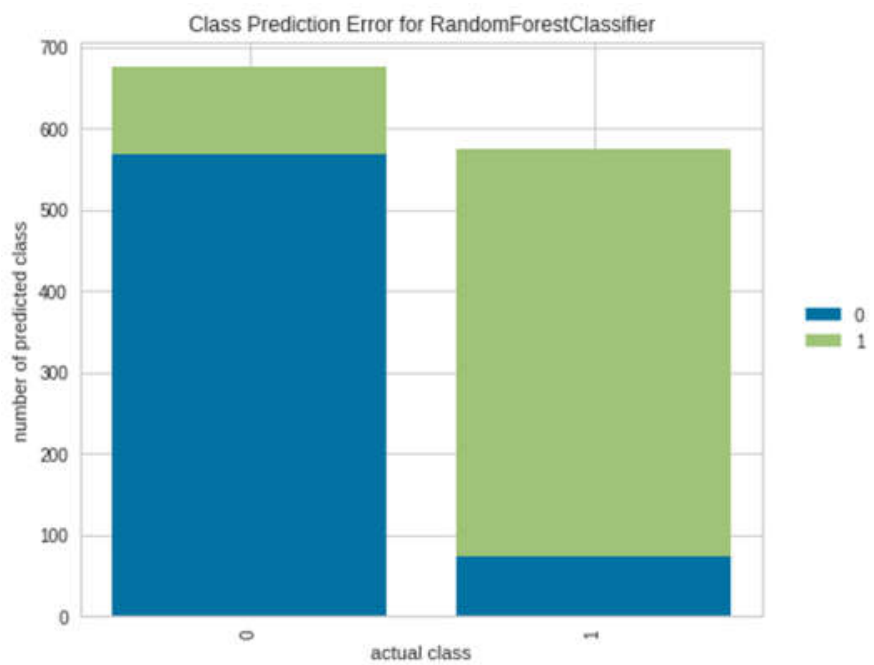

Fig. 7 Class prediction error

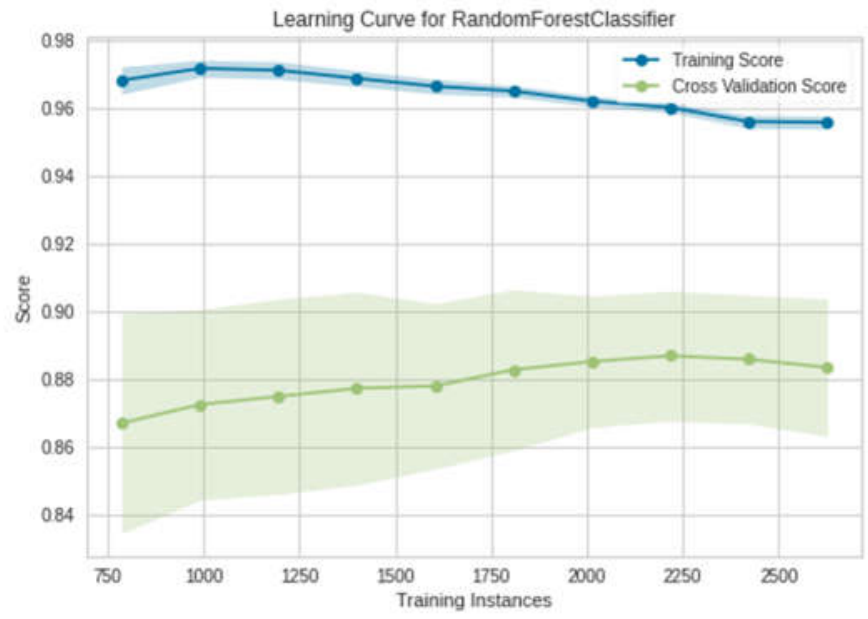


Fig. 8 Learning curve

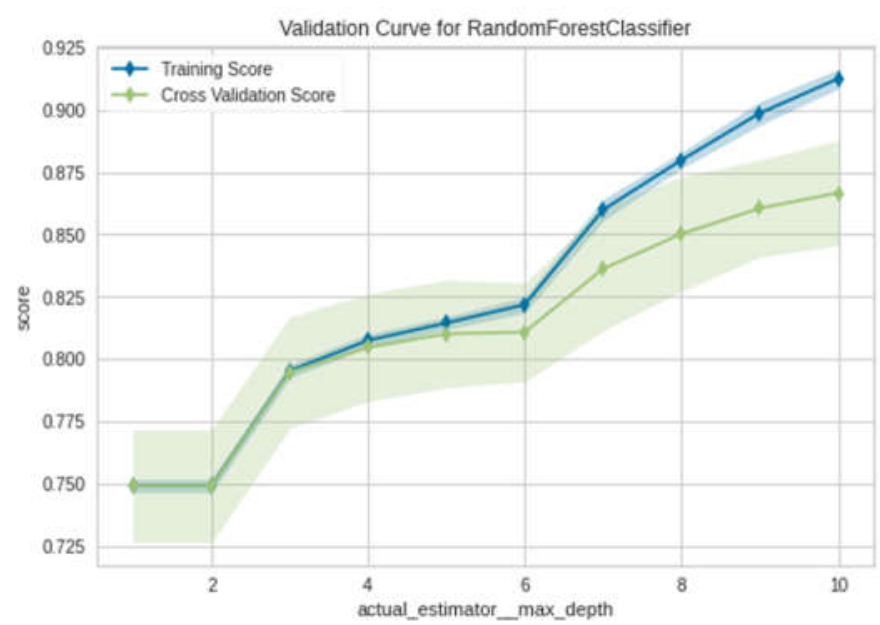

Fig. 9 Validation curve

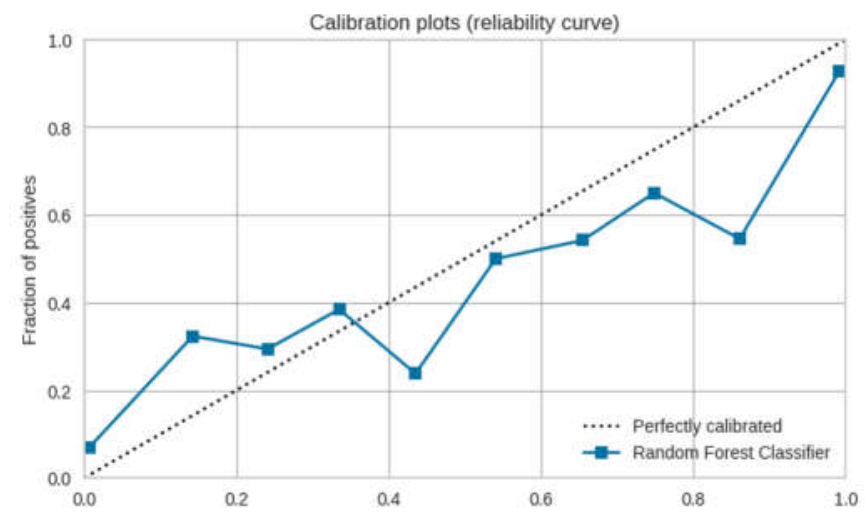

Fig. 10 Calibration plot

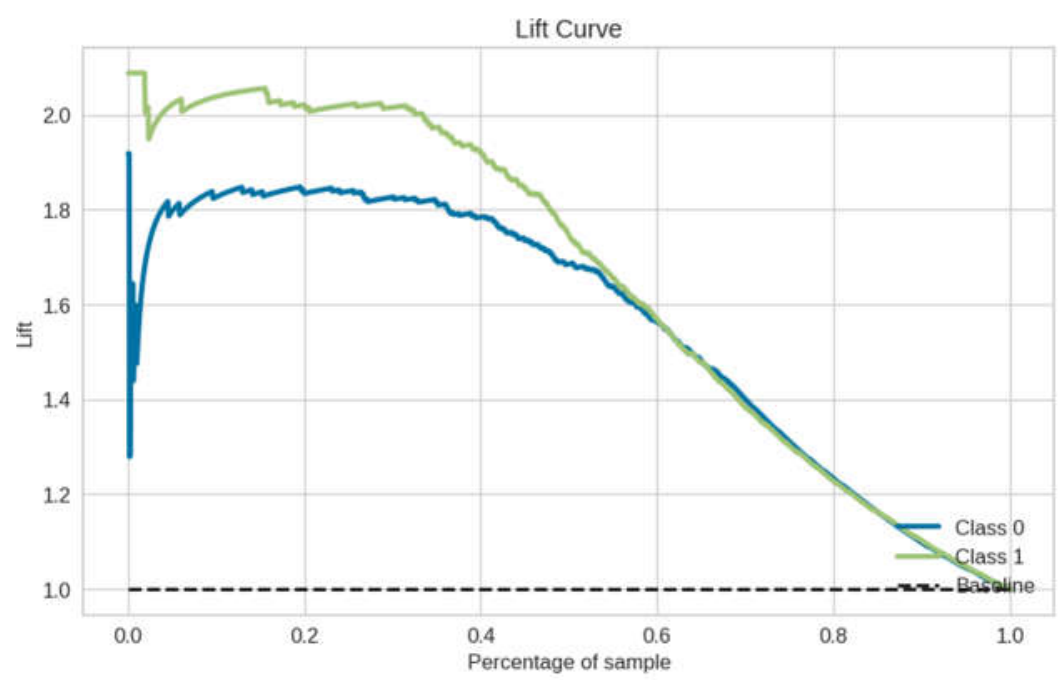


Fig. 11 Lift curve

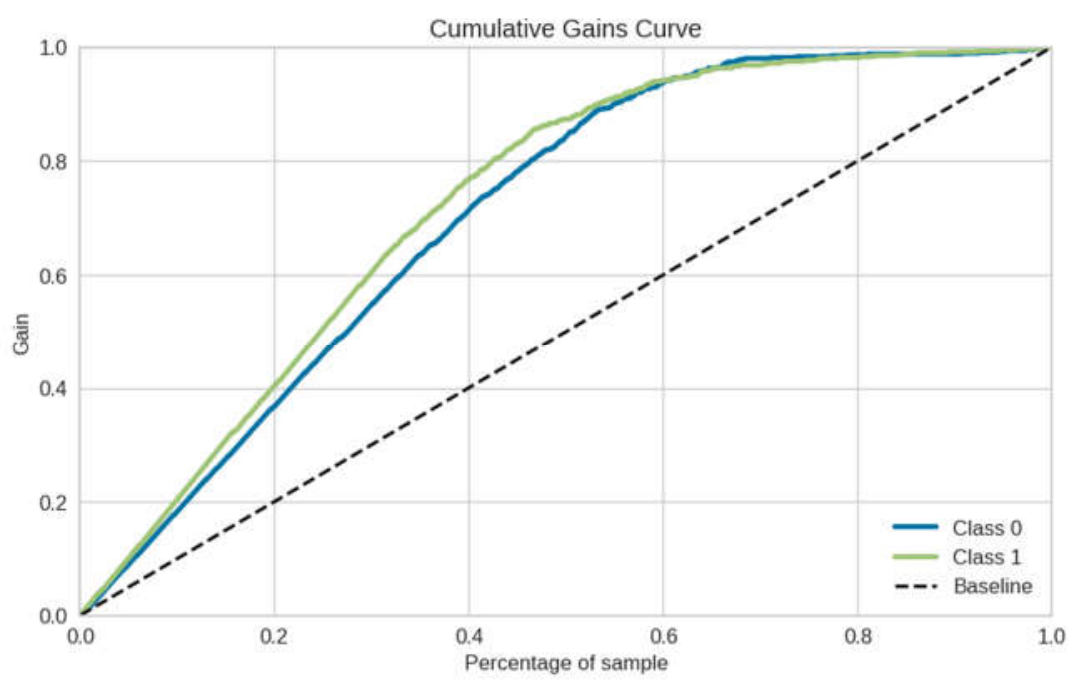

Fig. 12 Cumulative gains curve

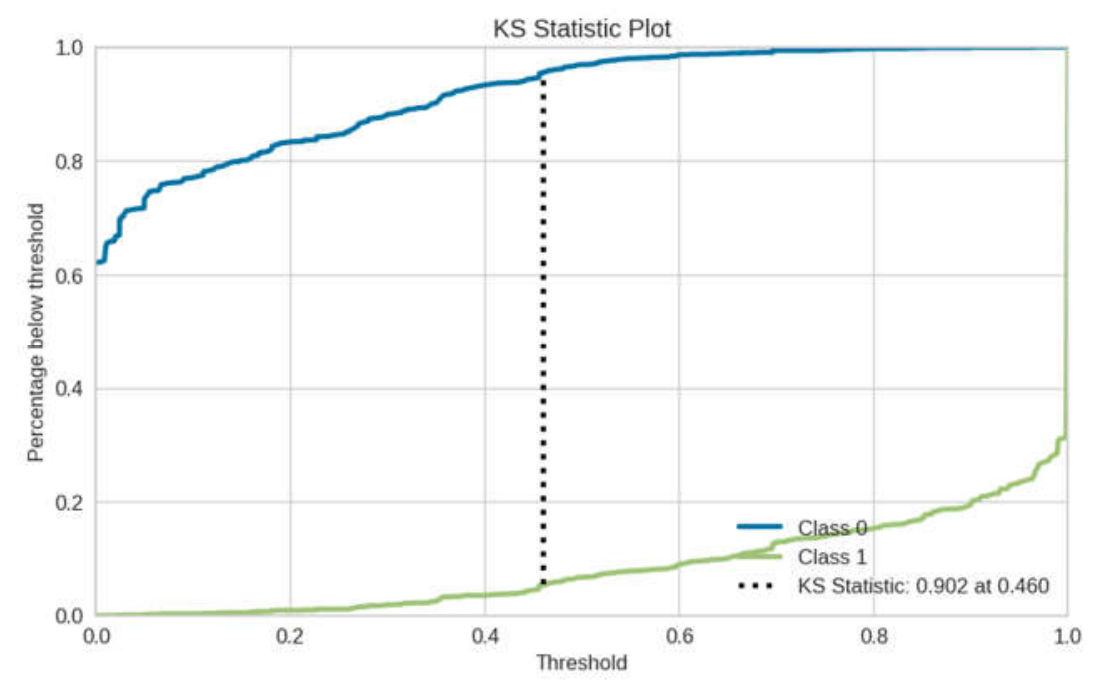

Fig. $13 \mathrm{KS}$ statistic plot 